\title{
University teachers' perspectives on the role of the Laplace transform in engineering education
}

Margarita Holmberg (née González Sampayo) ${ }^{\mathrm{a}, \mathrm{b}}$ and Jonte Bernhard ${ }^{\mathrm{b}}$

${ }^{a}$ Escuela Superior de Ingeniería Mecánica y Eléctrica, Instituto Politécnico Nacional, Mexico City, Mexico.

${ }^{b}$ Engineering Education Research Group, Department of Science and Technology (ITN), Linköping University, Campus Norrköping, SE-601 74 Norrköping, Sweden.

Contact: Jonte Bernhard E-mail: jonte.bernhard@liu.se

Preprint of a paper published in European Journal of Engineering Education doi: 10.1080/03043797.2016.1190957

Please consult the published paper if citing. 


\section{University teachers' perspectives on the role of the Laplace transform in engineering education}

The Laplace transform is an important tool in many branches of engineering, for example electric and control engineering, but is also regarded as a difficult topic for students to master. We have interviewed 22 university teachers from five universities in three countries (Mexico, Spain and Sweden) about their views on relationships among mathematics, physics and technology/application aspects in the process of learning the Laplace transform in engineering education.

Strikingly, the teachers held a spectrum of qualitatively differing views, ranging from seeing virtually no connection (e.g. some thought the Laplace transform has no relevance in engineering), through to regarding the aspects as intimately, almost inseparably linked. The lack of awareness of the widely differing views among teachers might lead to a lack of constructive alignment among different courses that is detrimental to the quality of engineering education.

Keywords: Engineering education research, Didactics (Pedagogy) of Higher Education, Electrical Engineering, Mathematics Education, Laplace transform, Constructive alignment. 


\section{Introduction}

Both students' learning and teachers' teaching can be seen as including the aspects 'what is learned/taught', i.e. subject matter, and 'how is it learned/taught', i.e. the process of learning and teaching (Booth 2008). For example, a central tenet in phenomenography and variation theory (e.g., Marton 2015) and the European didaktik ${ }^{1}$ tradition (Borrego and Bernhard 2011) is that what is taught and how it is taught are equally important. Furthermore, interest in subject matter has emerged in research related to constructive alignment theory (Biggs 1996) and 'how teachers conceive of what it is that students should learn is being seen as of, at least, equal importance to how that subject matter is taught' (Trigwell and Prosser 2014, 142).

However, until recently education research has focused more on students' (mis)conceptions or their understanding of subject matter (e.g., Berge and Weilenmann 2014; Streveler et al. 2008; Carberry and McKenna 2014; Baillie 2006), and their approaches to learning (e.g. deep and surface learning (Marton 1975), i.e. the what and how aspects of learners' learning rather than teachers' understanding. There has also been considerable research interest in how teaching should be performed, curricula organised and subject matter represented to improve students' learning (e.g., Baillie and Bernhard 2009; Bernhard 2010; Edström and Kolmos 2014; Finelli, Daly, and Richardson 2014).

It is important to note that subject-matter (the object of learning) should not be understood, especially in engineering, solely as content in a narrow sense, but as encompassing 'phenomena, concepts, theories, principles, [and] skills' (Booth 2004, 11)

\footnotetext{
${ }^{1}$ The spelling used in German and the Nordic languages is deliberately used to distinguish the
} 
and can also be regarded as including (inter alia) 'capabilities' and 'values' (Bowden 2004; Marton, Runesson, and Tsui 2004).

Marton, Runesson, and Tsui (2004) use the term 'object of learning' when referring to subject-matter and claim that the way teachers enact the object of learning 'defines what is possible to learn in the actual setting'. Thus, it is clearly important to study teachers' views on subject matter. This importance is corroborated by findings of connections between teachers' conceptions of subject matter, how it is taught and students' approaches to learning. Accordingly, several studies (e.g., Prosser et al. 2005) have addressed teachers' understanding of, and views on, subject matter, but largely at general levels. Hence, we maintain that there is a need to investigate in more depth university teachers' understanding of subject matter, i.e. the what of learning, on more fine-grained and contextual levels, particularly what aspects known to be important but difficult for students to master in particular subjects.

An important element of engineering subject matter is mathematics. It is learned as a subject in itself in mathematics courses and used as a tool in most branches of engineering. Hence mathematics is applied in some way or another in most engineering courses. One of the mathematical tools that is important in many branches of engineering, and physics, is the Laplace transform (Carstensen 2013; González Sampayo 2006), as discussed in more detail below. The theory behind the Laplace transform and especially its applications are not only taught in courses in mathematics, but typically also courses on electric circuit theory, control theory, signals and systems, solid mechanics and many other topics. For these reasons we have investigated, in depth, university teachers' views of the Laplace transform in engineering education. 
In the following sections we briefly present, as further background to the present study, the didaktik tradition and the Didaktik triangle in $\S 2.1$, constructive alignment in $\S 2.2$, views on subject matter in $\S 2.3$, and the role of the Laplace transform in engineering education in $\S 2.4$. In $\S 3$ aims of the study and the research questions are presented and in the methods chapter $(\S 4)$ the choice of method, selection of participants $(\S 4.1)$, data collection methods $(\S 4.2)$, and methods used to analyse data and represent the results $(\S 4.3)$ are described. $\S 5.1$ presents participating teachers' views on the role of the Laplace transform in engineering education, and $\S 5.2$ their views on students' difficulties in mastering the Laplace transform. Finally, in $\S 6$, we present a short discussion and conclusion.

\section{Background}

\subsection{Didaktik tradition and the Didaktik triangle}

The 'what-question' of learning and teaching is important in the 'didaktik' tradition stemming from Comenius (1657). This tradition has strongly influenced European educational research in general and European engineering education research in particular (Borrego and Bernhard 2011). A representation of the triadic relationship between the student (learner), the teacher and subject matter recognized and applied in this tradition is the Didaktik triangle (e.g. Künzli 2000, 48-49). The triangle is displayed in figure 1 and is used as a model for analysing phenomena in education such as educational emphases, and their variations, in relation to focal subject matter. In line with the focus of this paper, as discussed in more detail below, we have further represented the considered subject matter as a triadic relationship between mathematics, technology and physics. 


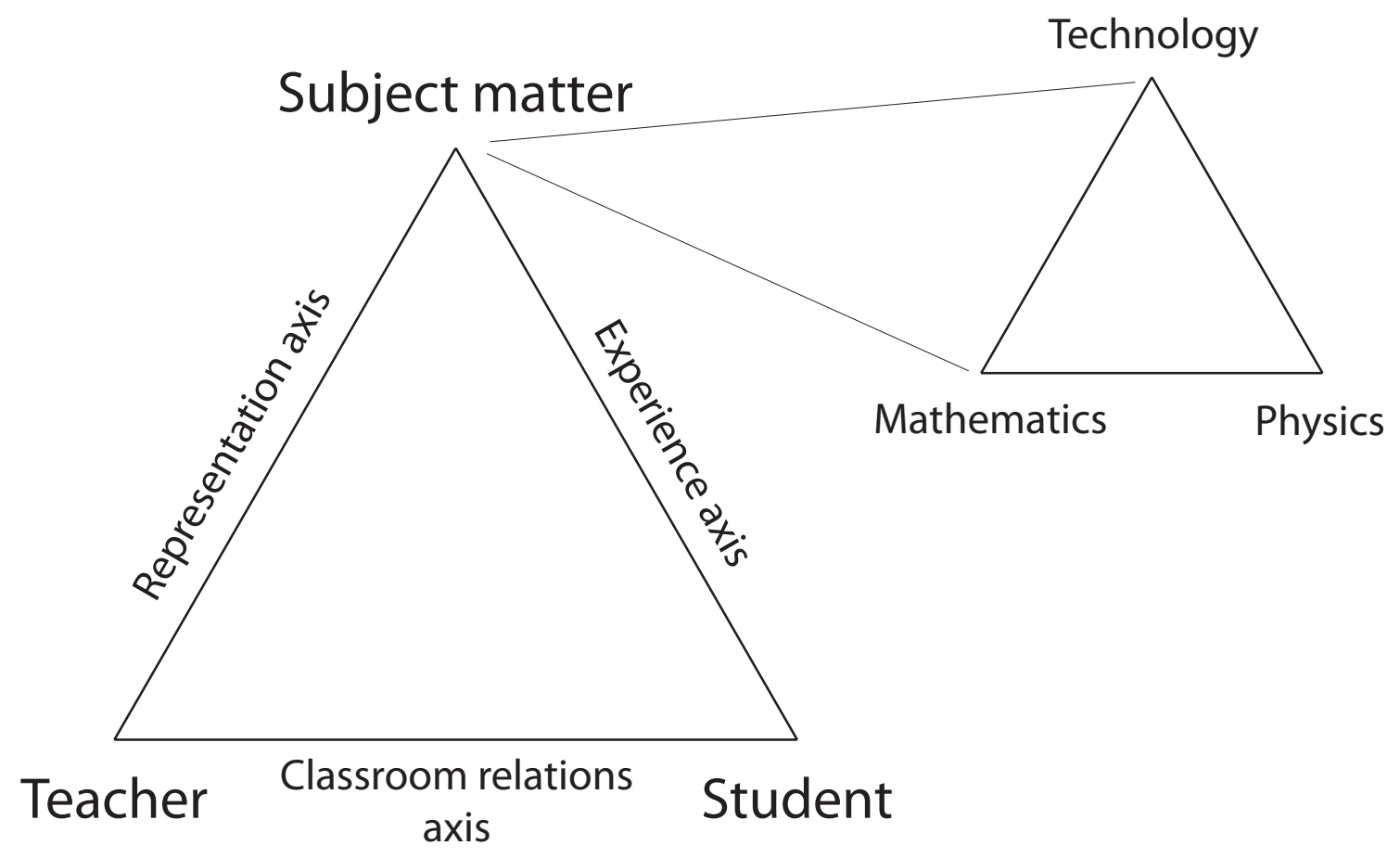

Figure 1. The Didaktik triangle used in the analysis, with subject matter regarded, in the context of this paper, as a relation between mathematics, physics and technology.

In education research the focus may be on any of the triangle's corners, i.e. the teacher (also called agency in some research fields, for example computer-supported teaching), student or subject matter, or on one of the axes connecting the corners. The representation, experience and classroom intercourse axes link teachers with content, students with content, and students with teachers, respectively. In education research the student-teacher (classroom intercourse) and student-subject matter (experience) axes have been more frequently investigated than the teacher-subject matter (representation) axis.

However, an important purpose of the Didaktik triangle is to display the triadic interrelationships between the elements (teacher, student and subject matter) and their connections (the axes), thereby facilitating analysis. It is commonly noted that it is 
impossible to change any 'corner' element or connection of this triadic relationship without affecting the other elements and connections. Accordingly, it has been amply demonstrated that teachers' epistemic views and their views on subject matter are important for the content and quality of student learning. For example Pajares (1992) found that teachers' classroom practices are significantly influenced by their beliefs about teaching and learning, and that their beliefs influence their practices more strongly than their knowledge of a particular content. Moreover, Linder (1992) showed that metaphysical realism (overt or covert) in teaching of physics can encourage inadequate learning strategies among students such as rote-learning of facts and discourage coherent understanding. In a further exploration of these relationships, Mulhall and Gunstone (2008) interviewed five physics teachers whose teaching was classified as 'traditional' and five whose teaching was classified as 'conceptual', based on observation of classroom practices. They found that the typical 'traditional' teacher believes that knowledge in physics is unproblematic and knowledge is discovered by applying 'the scientific method'. Such teachers consider physics to be mathematical, abstract and superior to other disciplines. In contrast, 'conceptual' teachers think that the concern of physics is to find useful models to explain the real world. They see knowledge as problematic, since all models have limitations, hence many models may have some valid elements, and the role of mathematics in physics is to serve as a language used to express ideas in physics.

\subsection{Constructive alignment}

Constructive alignment (Biggs 1996) has quite recently emerged as a powerful approach for improving the quality of students' learning. The underlying idea is that there should 
be 'maximum consistency throughout the system' (Biggs 1999, 64), hence curricular elements such as object of study, intended learning outcome, teaching approach and focus of assessment should be aligned and mutually supportive. Learning is seen as taking place in an 'interactive system [that] has to be understood as a whole.

Components have to be considered as they affect each other, not as acting separately or additively' (Biggs 1999, 61, emphasis in original). Thus, this approach shares ideas with the tradition and concepts underlying the Didaktik triangle, notably the impossibility of altering one component without effecting all the other components.

An example of how elements affect each other is that for many students the focus of assessment in exams is a more important driver of their learning activities than the intended learning outcomes. For example, if questions on exams mainly test memorisation and low-cognitive-level reasoning most students do not study to understand whatever the instructor says in lectures. Thus, according to Biggs (1999), the main reason why students adopt a surface approach to learning (Marton and Säljö 1976) is a lack of alignment.

However, most literature related to constructive alignment has primarily addressed the teaching approach or focus of assessment (see, Biggs and Tang 2011). For example, using a phenomenographic research methodology (e.g., Marton 1988) Trigwell, Prosser, and Waterhouse (1999) related teachers' qualitatively differing conceptions of teaching with qualitatively differing approaches to learning their students reported. The results indicate that students are more likely to report a surface approach to learning when their teacher describes his/her approach to teaching as transmitting knowledge. 
Trigwell and Prosser (2014, p. 143) note that 'even if all three elements [intended learning outcomes, teaching approach and assessment focus] are aligned, how well the students learn may be associated with the quality of each of the aligned elements'. In a similar vein, Prosser et al. $(2005,138-139)$ saw a problem in the 'little attention paid to ways in which university teachers understand the subject matter they are teaching and how that relates to their teaching and their students' learning'. They interviewed 31 experienced university teachers, including roughly equal numbers representing four disciplinary domains (social science and humanities, business and law, science and technology, and health sciences). The interviews focused on the teachers' understanding of their subject matter and connections among parts, how they saw that their subject matter fitted into broader fields of study, and how they described their teaching. Using phenomenographic methods Prosser et al. (2005) then identified five qualitatively different ways of experiencing subject matter, designated $A-E$, as briefly described below:

In $A$ subject matter is seen as a series of facts and/or techniques with atomistic structure. In $B$ the structure is still atomistic, but subject matter is seen as a series of concepts or topics. In $C$ and $D$ subject matter is seen as a series of concepts or topics as in $B$, but structured through linked internal relationships (in $C$ ) or as aspects of an integral whole (in $D$ ). Finally in $\mathrm{E}$ the structure of subject matter is seen as a coherent whole and the focus in subject matter is on the underlying theories within which concepts and procedures are constituted.

Prosser et al. (2005) also identified five qualitatively different views, $A-E$, related to teaching and learning. The indirect object of teaching is information transfer in $A$ and $B$, concept acquisition in $C$, conceptual development in $D$ and conceptual 
change in $E$. Furthermore, they identified five qualitatively different views, $A-E$, related to the object of study constituted in the topic. Briefly, knowledge is seen as given in views $A-C$ (with different structures), while in $D$ and $E$ knowledge is seen as constructed and/or problematic (in $D$ it is placed within the discipline while in $E$ it is placed in learning beyond the discipline).

The sets of categories briefly described above were also related to each other by Prosser et al. (2005). Teachers who described the object of study as involving integrated elements, expressed a holistic view of subject matter, placed it in a wider context, and saw knowledge as problematic rather than something that could be taken for granted, generally described their teaching as based on conceptual development or conceptual change approaches. In contrast, teachers who saw the object of study as being constituted in more unrelated and atomistic manners were more likely to describe use of more transmissive teaching approaches.

The results presented by Prosser et al. (2005) suggest a close link between how teachers think about the object of study and how it is taught (cf., Martin et al. 2000), while the results of Trigwell, Prosser, and Waterhouse (1999) indicate that how teachers think about teaching and the approaches to learning students take are closely connected. Thus, exploration of the alignments between the curriculum elements object of study, intended Learning outcome, teaching approach and focus of assessment can be seen as one way to address the key what-questions in education; what is taught (by teachers) and what is learned (by students).

\subsection{Views on subject matter}

Straesser (2007) has used the Didaktik triangle to discuss the relevance of the 
mathematics students are often taught, especially in vocational and workplace contexts, and criticized the general invisibility of such practical aspects in mathematics education research. Booth (2008) has investigated engineering students' views on the nature of mathematics, and Booth and Ingerman (2002) have investigated first year engineering physics students' views on the nature of subject matter in their first year of studies. The results confirm an assertion by Pollak (1979), that mathematics is commonly seen as being distinct from 'the rest of the world'. Although we are increasingly using mathematics in diverse applications it is often seen as lacking relevance by students (e.g., González Sampayo 2006). Even engineering students often regard mathematics as being detached from 'the engineering world' (Winkelman 2009). Niss (1994) coined the term 'relevance paradox' for this phenomenon. In physics education research the nature of the relationship between mathematics and physics has been addressed in several studies. Dray and Manogue (2005) remind us that the "way mathematicians view and teach mathematics, and the way mathematics is used by physicists and other scientists, are completely different; we speak different languages, or at least different dialects'. Furthermore, they stress that the same vocabulary is sometimes used, but with different meanings.

\subsection{The Laplace transform in engineering education}

The Laplace transform is an important mathematical tool in many branches of engineering and science, for example, electric and control engineering. Briefly, Laplace transforms enable the transformation of differential and integral equations into algebraic equations that are more mathematically convenient to handle and solve. Furthermore, they allow the use of generalized forms of laws and relationships such as Ohm's law, 
Kirchoff's laws, voltage division etc. when investigating transients and AC-signals, which have similar structure to those valid for DC-circuits. Indeed, as pointed out in several works by Grubbström and co-workers (e.g. Grubbström 1967) Laplace transforms have applications in any field where differential equations are used to represent relations between concepts and variables, e.g. economics, production technology and management science.

Nevertheless, despite the importance of the Laplace transform students often ask questions like 'Why do I have to use the Laplace transform to solve an electric circuit?' (González Sampayo 2006, 61). One of the reasons that such views are expressed may be that students find it difficult to conceptualise and understand what they are doing when they use the Laplace transform. Indeed, Carstensen and Bernhard (2004) found that 'In many engineering programs at college level the application of the Laplace transform is nowadays considered too difficult for the students to understand... ' and González Sampayo (2006) concluded after investigating teachers' and students' views that it is one of the most difficult topics for students to grasp when learning electric circuit theory. Similarly, Carstensen (2013) and Carstensen and Bernhard (2008, 2009) observed engineering students' difficulties in grasping transient responses in electric circuits and the use of Laplace transforms. Furthermore, in the context of ACelectricity, Bernhard and Carstensen (2002), and more recently Kautz (2011) and Bernhard et al. $(2010,2013)$ found that engineering students had difficulties understanding phasors ( $j \omega$-methodology), phase and the use of complex numbers. This is relevant because $j \omega$-methodology also transforms differential equations into algebraic equations, although it is limited to sinusoidal signals (periodic signals can be seen as a superposition of sinusoidal signals through the use of Fourier series) and conditions in 
which steady-state is reached. A common finding of all the cited studies is that students have problems establishing relationships between the 'object'/ 'event' 'world' and the 'theory'/'model' 'world'. Indeed, various authors (e.g. Tiberghien 1999) have found that grasping these links is the most difficult task for students, hence it is important to make these links explicit in education (cf., for example Roth and Bowen 2001; Kaput 1987; Carstensen and Bernhard 2016).

\section{Aim and research questions}

The Laplace transform is an important tool in many branches of engineering, especially electrical engineering, in which we have teaching experience. The theory behind the Laplace transform is usually taught in mathematics as well as in engineering courses, while its application as a tool is predominantly taught in engineering courses. Previous research studies, such as Carstensen and Bernhard (2004), indicate that the Laplace transform is seen as a difficult topic to learn. In addition, several previous studies (e.g., Linder 1992; Martin et al. 2000; Marton, Runesson, and Tsui 2004; Prosser et al. 2005; Mulhall and Gunstone 2008) have demonstrated connections between teachers' views on subject-matter and students' learning. However, as mentioned above, previous studies have addressed teachers' views on subject-matter in largely general terms, there have been few more specific studies, and no analyses (to our knowledge) of university teachers' views on the Laplace transform as a subject of study in engineering education.

For these reasons it is both interesting and important to study teachers views' on the Laplace transform as subject-matter, phenomena lying on the representation (teacher-subject matter) axis in the Didaktik triangle (see $\S 2.1$ and figure 1). According to Künzli (2000, p. 48) 'the representation axis ... can be treated in two different ways: 
(a) as a doctrinal interpretation, which gives content priority over the teacher, or (b) as a magisterial interpretation, which gives the teacher priority over content' (italics in the original). Since we are investigating teachers' views, the foci of our study can be regarded as teachers' magisterial interpretations of subject-matter in the terminology of Künzli (2000), or as being related to, but not identical to, the intended object of learning in the terminology of Marton, Runesson, and Tsui (2004). However, it should be noted that this distinction would not be relevant for those teachers who, according to Prosser et al. (2005) and Mulhall and Gunstone (2008) for example, see subject-matter as unproblematic. Furthermore, since we are investigating views on the Laplace transform as a topic within engineering education we are interested in teachers' views on the triadic relationship between 'mathematics', 'physics' and 'technology' in this context. Here 'mathematics' refers to the role/importance of the Laplace transform in pure mathematics, 'physics' to its role/importance as a tool for describing natural phenomena, and 'technology' to its role/importance as a tool in applied fields. This triadic relationship is illustrated by a smaller triangle in figure 1.

This study is part of a larger investigation of students' and teachers' views on the role of the Laplace transform in engineering education and students' understanding of transients and Laplace transforms within electrical engineering (e.g., González Sampayo 2006; Carstensen 2013; Carstensen and Bernhard 2008). In another study using data from the same interviews we have investigated teachers' views if (and if yes why) the Laplace transform is a difficult topic for students to learn. In that study we explored teachers' views on the experience (subject matter - student) axis in the Didaktik triangle. We have also investigated students' views, and results of that research will be reported elsewhere. 
In the study presented here we are addressing the question: What different views are held by university teachers on the relationship between the 'mathematics', 'physics' and 'technology' aspects in the context of engineering students' problems in learning to use the Laplace transform?

\section{Methodology and context of the study}

We have addressed our research questions regarding differences in university teachers' concepts on the nature of the Laplace transform in the context of engineering students' learning using qualitative interviews, in order to exploit their high capacity to provide insights into people's views.

\subsection{Participants}

We applied a purposeful sampling strategy (Creswell 2012, 206-208) in an attempt to obtain a sample of informants who could contribute informed perspectives of the focal subject matter, representing a wide part of the full diversity of university teachers' views. In total, 22 university teachers volunteered to participate in the study. They were all experienced teachers teaching topics related to the Laplace transform at five major technical universities in the countries of Mexico (one university), Spain (three universities) and Sweden (one university). Teachers teaching transform theory as a mathematical subject and as well teachers teaching courses where the Laplace transform was applied were represented in the sample. To preserve the anonymity of the informants' further detailed information (e.g. country, institution, disciplinary background, courses taught) are not provided among the results describing the views of the teachers. 


\subsection{Data collection method}

In this study the 22 university teachers were interviewed, on the role of the Laplace transform in engineering, using a semi-structured approach. Kvale (1996, pp. 5-6) describes semi-structured interviews as 'an interview whose purpose is to obtain descriptions of the life world of the interviewee with respect to interpreting the meaning of the described phenomena'. In this case the focal phenomena were the teachers' perspectives regarding the role of the Laplace transform in engineering. They were asked questions such as 'What is the importance of the Laplace transform in engineering education?', 'What are the difficulties hindering students from learning the Laplace transform?', 'What uses does the Laplace transform have for solving real world problems?' and 'What is its importance for students' future professions?' The interviews were conducted in English in Sweden, and in Spanish at the other universities. The interviews followed standard procedures for interviews in qualitative research (e.g., Kvale 1996), they were recorded and later transcribed and analysed using an approach described below.

\subsection{Methods used to analyse data and represent results}

As already stated, in the analysis presented here we were particularly interested in teachers' views on the relationships between three aspects of the process of learning the Laplace transform: Mathematics, the role/importance of the Laplace transform in pure mathematics; Physics, its role/importance as a tool for describing natural phenomena; and Technology and/or application, its role/importance as a tool in different applied fields, e.g. economics or automatic control. Parts of the interviews concerning topics that are not related to the research questions addressed in this study are not considered 
here.

To analyse, represent and summarise views on these aspects the university teachers expressed in the interviews we construed 'perspective-dependent relational diagrams', using a method developed by us (González Sampayo 2006, Appendix D; Holmberg and Bernhard 2008). To illustrate the method we present a transcript of one of the interviews below, together with the relational diagram construed from it. The interviews were numbered, and for convenience specific interviewed teachers are sometimes referred to using corresponding numbers (e.g. the teacher interviewed in Interview 15 is referred to as Teacher 15 , etc.).

Transcript from interview 15: I think that is very difficult to divide into three aspects. I think they are all connected and you cannot divide them very clearly. I mean, you need first to understand what the Laplace transform is to be able to use it; you must then understand...I cannot see very much the physical aspect of the Laplace transform, honestly, I mean, I cannot see very much the difference between physical and technological aspects. At least, from my point of view I mean the Laplace transform is a transform, so it is a mathematical definition with properties that make it possible to change, to study some problems in the Laplace domain instead of the time domain that would be very much more difficult for us [to address]. [This is] because the transfer function makes it much easier to study the proprieties of a system. I cannot see very much the difference between physics and technology? Could be (program)? One that I have understood how you can use in some... although of course you can use any program, I can think only of Matlab, because it is one that I use ... but it is only a way of computation. Matlab only makes computation faster as you don't have to do it by hand, but still one has to understand what is behind it, in my opinion, otherwise the risk is that you can give a wrong interpretation of the results if you just do not have a clear idea what the Laplace transform represents. That is it is important to understand why and how a mathematical definition can be used, and then of course you can also use the program, that is the easier step. 
To construct a perspective-dependent relational diagram from this transcript we extract the most important points (in the context of the focal research question):

(1) I think that is very difficult to divide the topic into three aspects.

(2) I cannot see much difference between physical and technological aspects.

(3) The Laplace transform is a mathematical definition.

(4) I can use Matlab, but it is only a means of computation The resulting diagram is shown in figure 2 .

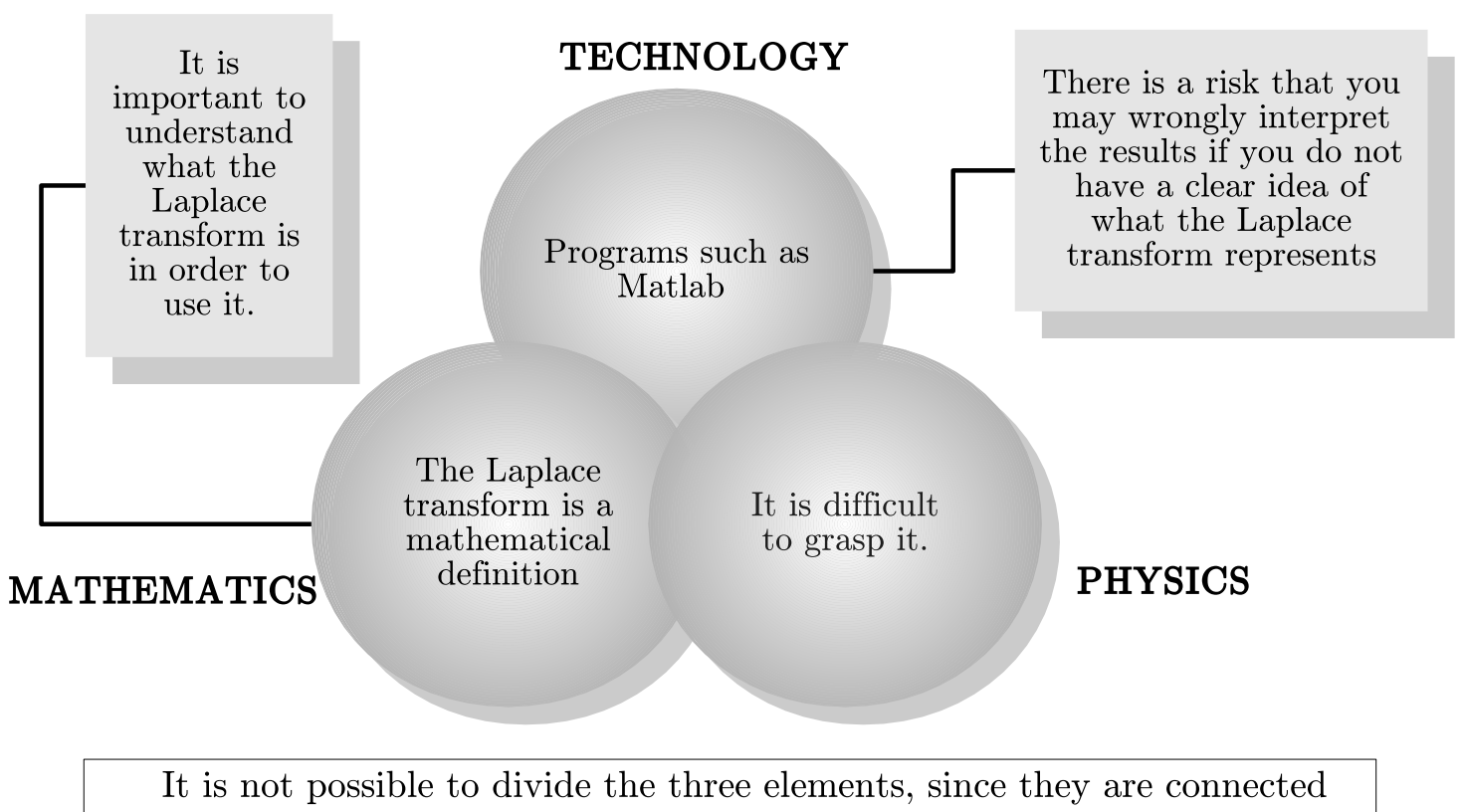

Figure 2. Diagram of relations as perceived by Teacher 15, based on the transcript of Interview 15.

The method we have used is analogous to phenomenography (Marton 1981) in the sense that teachers' qualitatively differing conceptions of some aspect of reality is investigated. However, in a phenomenographic analysis of interviews the resulting transcripts are commonly treated as a whole, i.e. statements are usually no longer connected to an individual but as part of a 'collective'. In this collective the researcher 
identifies categories of qualitatively different conceptions or views of the aspects of reality investigated. A teacher educating a group of students will probably meet all, or at least most, of these qualitatively different conceptions in the group. In contrast, students typically have a single teacher and thus meet singular instructors' views. Therefore, in this study we have chosen to represent the teachers as individuals.

\section{Results}

\subsection{Teachers' view of the role of the Laplace transform in engineering}

The teachers were asked about their views on the relationships between physics, mathematics and technology, as detailed in the methodology section above. The diagrams of relations construed from the interviews with six of the teachers are presented in figures $2-7$. However, we have not included the original transcripts used to construe these diagrams, except for Interview 15 (figure 2$)^{2}$.

The presented diagrams of relations clearly show that the teachers expressed very different views. For example, one teacher (Teacher 15, figure 2) regarded all aspects as integrated and impossible to separate, while another (Teacher 4, figure 3 ) did not see any relation between the aspects. In the interviews several teachers indicated beliefs that it is essential to stress the scope for applying the Laplace transform, but that

\footnotetext{
${ }^{2}$ The transcript from teacher 15 's interview is presented solely to illustrate our method for analysing and representing interviews, rather than because we think that his or her views are more important than those of any other teachers.
} 
use of many different transforms such as Fourier- and Laplace transforms is confusing for students.

\section{MATHEMATICS}

Is not useful for engineering aspects

\section{TECHNOLOGY}

The Laplace transform is used to describe system addressed in systems control

\section{PHYSICS}

The Laplace transform is not important in physics

Differential equations are much more important for building physical models than the Laplace transform

Figure 3. Diagram of relations as perceived by Teacher 4, based on the transcript of Interview 4.

The results obtained from analysing Interview 15, presented in figure 2, reveal that the teacher regarded all three subject-matter elements (mathematics, physics and technology) as being holistically integrated. In contrast, the results from Interview 4, presented in figure 3, show that the teacher regarded the three elements as being unconnected, and mathematics as not being useful in practice. 
Teacher 4 (figure 3) argued that the Laplace transform allows highly detailed mathematical analysis of systems, but it is not useful for engineering; differential equations are more relevant as they are generally used for describing systems when building physical models. In automatic control the Laplace transform can be used, but it is not even necessary for all automatic control. Differential equations can be used instead. Thus, from this perspective the Laplace transform is not important. It may be valuable for describing a system, but not necessarily for controlling it.

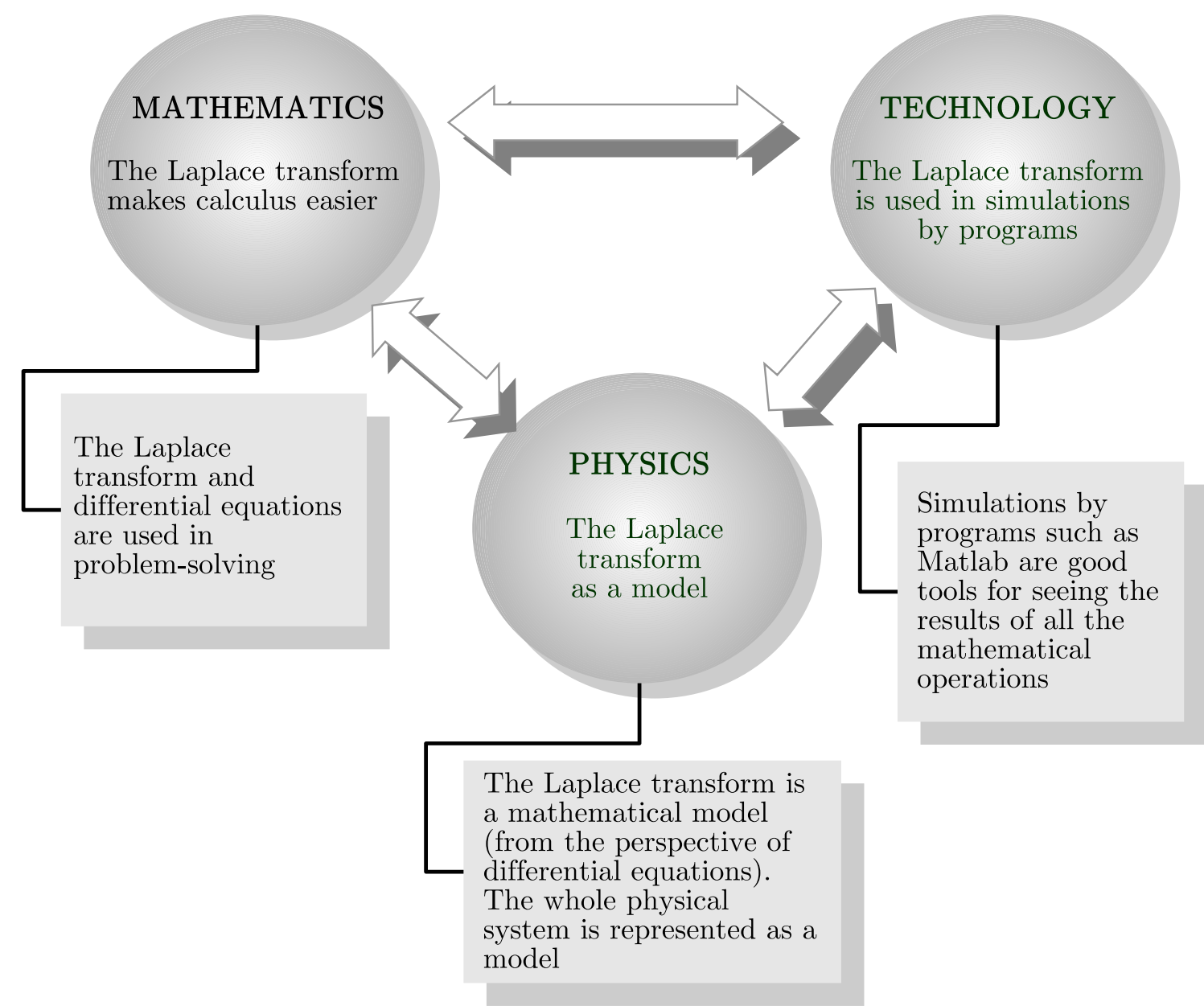

Figure 4. Diagram of relations as perceived by Teacher 5, based on the transcript of Interview 5. 
As illustrated in figure 4, Teacher 5 said that students can use the Laplace transform to facilitate mathematical calculations when solving automatic control problems, but it is not the only option. Alternatively, they can use differential equations, although the process is then more complex. In this teacher's view, the Laplace transform is more useful in physics, for mathematically simulating physical systems. For example, simulations may illustrate answers to questions that students ask, such as, 'Where can I see the results of mathematical operations I have applied?' Notably, Bode diagrams generated by Matlab can often vividly illustrate the results.

Teacher 5 can be regarded as having intermediate views between those expressed by Teachers 15 (figure 2) and 4 (figure 3). Whereas Teacher 5 regarded all elements as being connected, but still distinct, Teacher 4 saw no connection at all and Teacher 15 thought that the elements could not be separated.
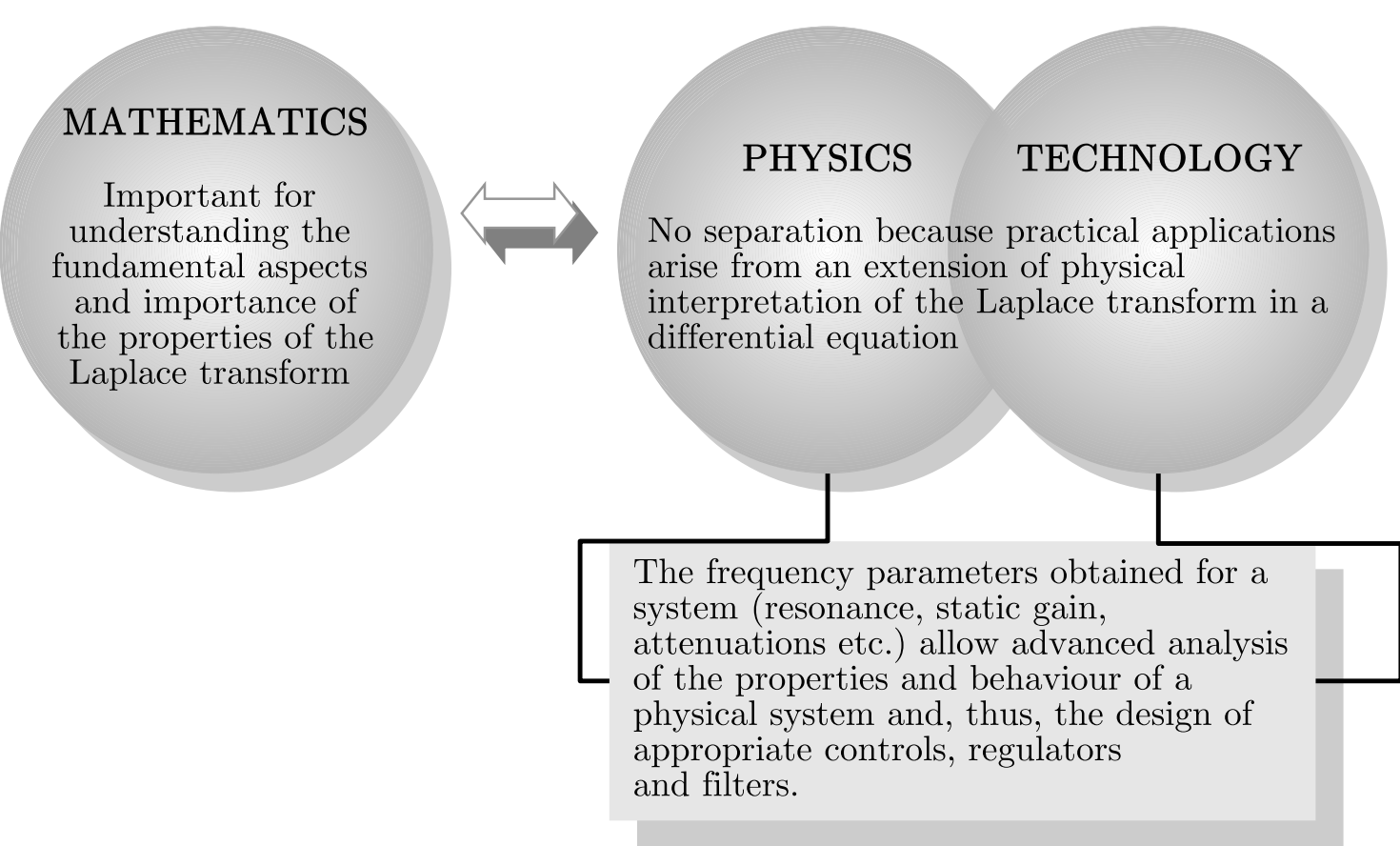

Figure 5. Diagram of relations as perceived by Teacher 8, based on the transcript of Interview 8. 
The diagram construed from the transcript of Interview 8 is presented in figure 5. The teacher claimed that it is important to understand the mathematical basis (fundamentals) of the Laplace transform and its properties for solving linear differential equations (polynomial relations). This understanding can be developed by studying every property individually in detail and analysing its advantages and disadvantages for solving differential equations. The teacher also asserted that technological and physical aspects should not be completely separated because practical applications arise from extending physical interpretations of Laplace transformation in differential equations. The Fourier transform is related to the addition of sinusoidal signals, and the Laplace transform to addition of exponential sinusoidal functions, hence it is important to understand the relations among time domains, frequencies and the Laplace transform.

Teacher 8 had similar views to Teacher 15 , in that he saw no separation between physics and technology. However, he regarded mathematics as a distinct, although connected, topic. 


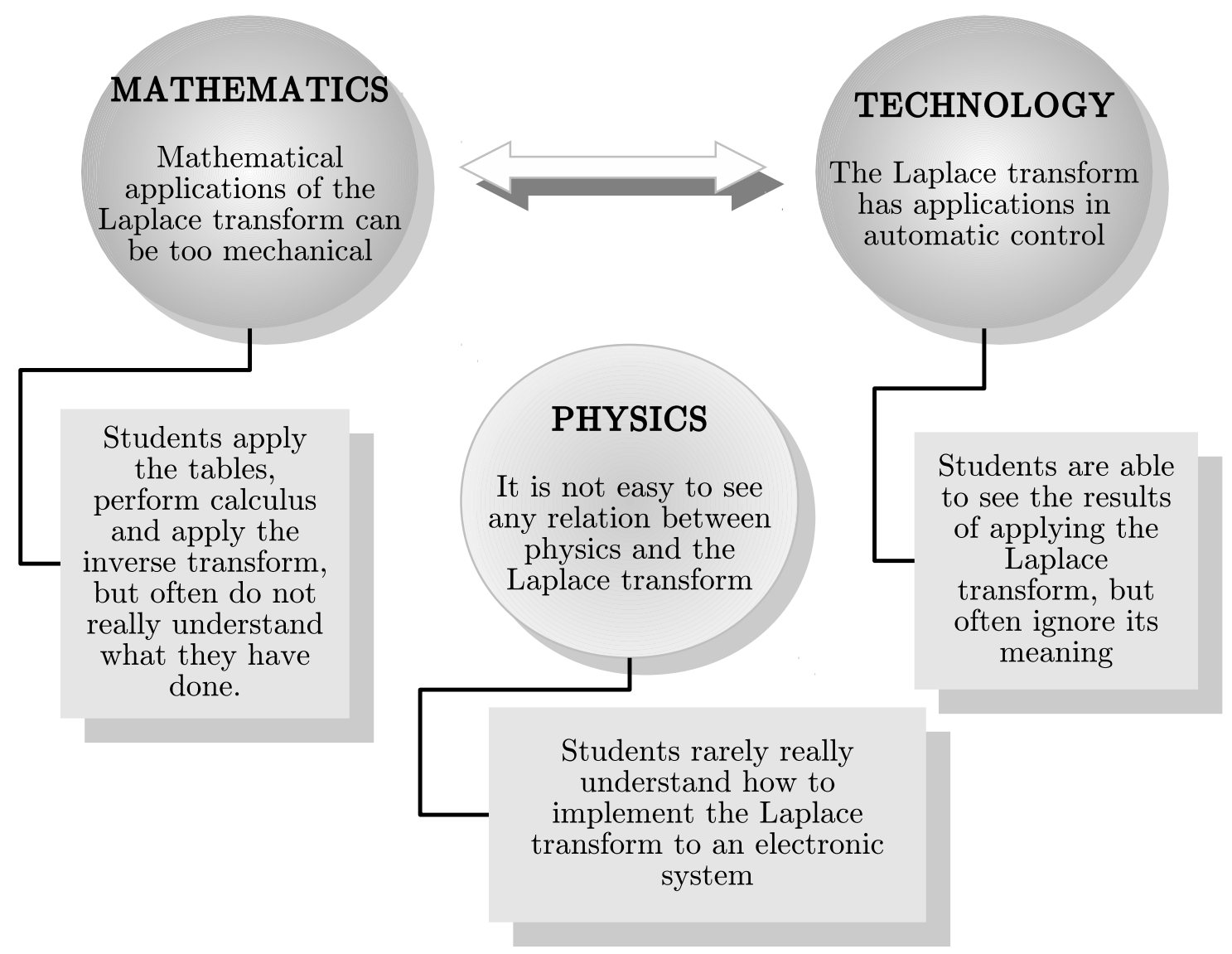

In automatic control we do not study the Laplace transform, we just apply it.

Figure 6. Diagram of relations as perceived by Teacher 12, based on the transcript of Interview 12.

Teacher 12 regarded mathematical development as a rather mechanical process, for example, students take the Laplace transform tables, do the transformation, then they realize the calculations and finally apply the inverse transformation, but at the end they often do not know what they have done. According to this teacher, in automatic control contexts at least, students notice that if they associate a pole with an ' $s$ ' or a zero they can modify the behaviour of a controller, but they often do not grasp what this does to 
the physical system. The physical element is poorly grasped because some students do not really learn to implement the Laplace transform in electronic systems.

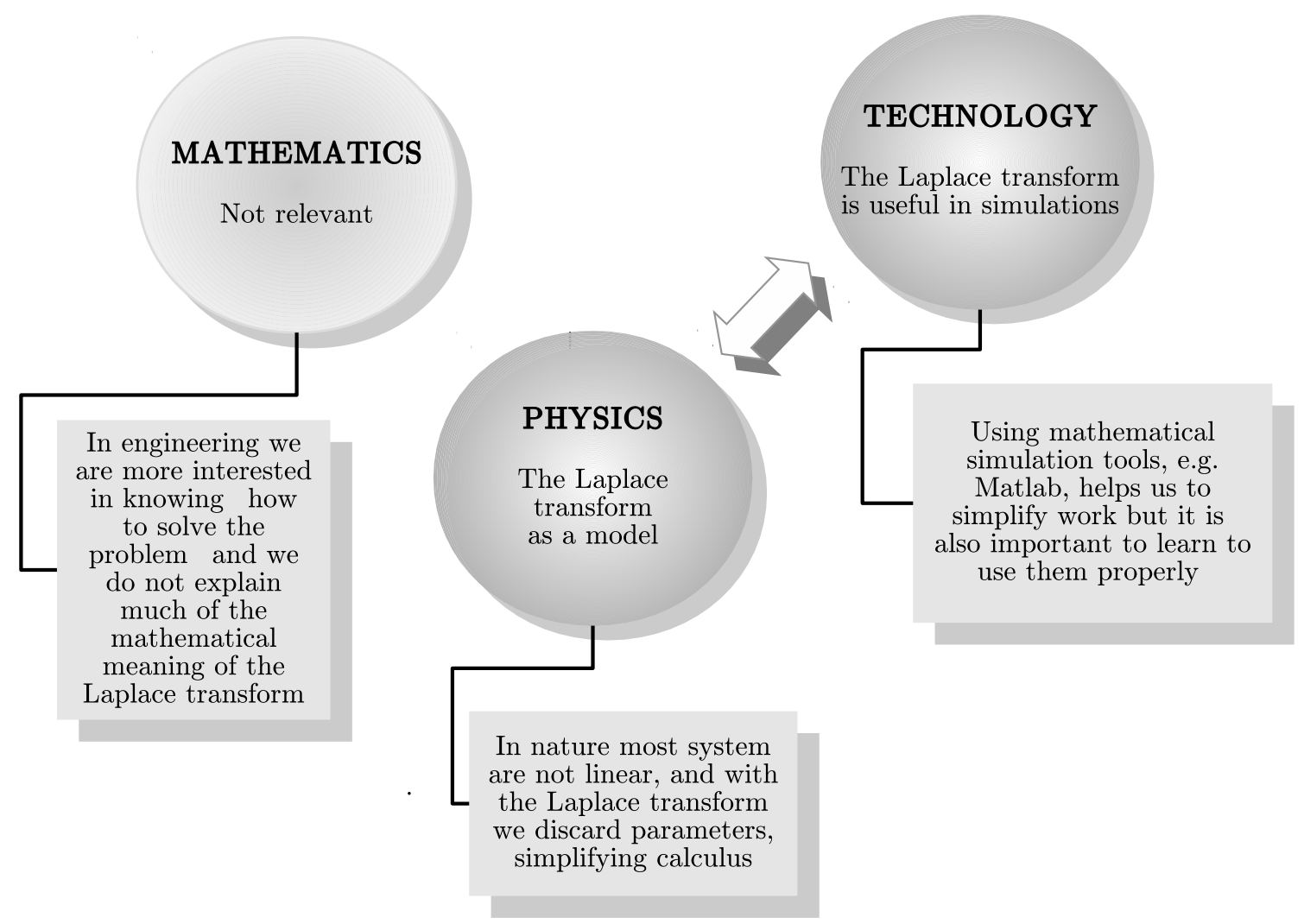

Figure 7. Diagram of relations as perceived by Teacher 17, based on the transcript of Interview 17.

The final comment in this presentation of the teachers' views is that Teacher 17 regarded a good background in using mathematics as essential for engineering students to develop high level understanding of the subject matter, which must include sound understanding of how to use the Laplace transform. However, the ability to use mathematics is relevant, rather than deep understanding of mathematics. In automatic control, for example, it may be more important to obtain 'correct' results than to understand all the properties of the tools we use. Their application is crucial, because in 
Nature most systems are non-linear, and use of the Laplace transform allows some parameters or characteristics to be neglected, greatly simplifying mathematical evaluations and calculus. However, although few mathematical tools simulate this process, when we talk with students about zeroes, poles, etc., we do so in a Laplacian context. When we talk about increasing or reducing frequency we also enter the Laplace domain (rather than time domain). This simplifies the work, and lets us relate applied procedures and observations to other tools, e.g. oscilloscopes. For these applications Matlab is a good simulation tool, but it is obviously important to learn to use it competently.

\section{Discussion and conclusion}

A striking conclusion of this study is that university teachers teaching or using the Laplace transform lack a unified view of both the difficulties involved in learning the Laplace transform and its importance. Although educational research has clearly shown the importance of making links explicit in teaching, the diagrams of relations construed in our study equally clearly show that teachers themselves have established very different links between, for example, mathematics, physics and technology. For example, Teacher 15 (see figure 2) regards mathematics, physics and technology as closely connected, almost inseparably fused. In stark contrast, Teacher 4 sees virtually no connection between mathematics, physics and technology (figure 3). For Teacher 8 technology and physics are fused, and linked to mathematics. Similarly, the other teachers see linkages, of varying closeness, between the elements. Strikingly, views expressed by the teachers regarding the relationship between mathematics, physics and technology correspond to views expressed in the literature. Furthermore, the results 
clearly show that some engineering teachers, as well as some engineering students, regard mathematics as being detached from the engineering world (e.g., Winkelman 2009) and irrelevant (e.g., Niss 1994).

It should be noted that, with few exceptions, we did not detect any national differences in our interview data. Furthermore, we could not see any clear relationship between teachers disciplinary background or the courses they teach and the views the teachers expressed in the interviews. On the contrary, teachers with similar background could express very different views. However, we did detect differences in views among teachers at the same institution. This implies that students are likely to meet teachers with diverse views on relationships between different aspects of such topics and, for example, meet teachers who do not see mathematics as relevant. Clearly, this also implies that there may be limited constructive alignment within a degree program. As discussed by Trigwell and Prosser (2014) this may lead to content for a degree being covered and assessed in qualitatively different ways and not 'understood as a whole' (Biggs 1999, 61). Furthermore, Trigwell and Prosser $(2014,151)$ suggest that 'part of the reason why teachers often feel that their students are not coming well prepared into their subjects may be because their colleagues teaching the prerequisite subjects are adopting no constructive alignment or limiting versions of it'. In a similar vein Sundlöf et al. noted that 'confusion might ensue [if teachers' and students'] conceptions of representations' ontological and epistemic status [conflict]'. Our results suggest that the different conceptions held by the teachers are, indeed, an expression of their different epistemological and ontological views. We here extend the claim by Sundlöf et al. (2003) and argue in line with the constructive alignment literature that conflicts in different teachers' conceptions' may also engender confusion. 
Educational research often focuses on students' conceptions and so-called misconceptions. Our study highlights the importance of also studying teachers' conceptions. When designing teaching-learning environments we must be equally aware of the diverse conceptions held by and students. The findings also show the importance of teachers explicitly discussing these matters with their colleagues. This does not mean that we believe all teachers should accept the same viewpoints, but that teachers should be aware that their colleagues may hold different views from their own. Indeed it is a strength for different disciplines to take different approaches and use different tools in their study of 'reality', and hold different epistemological views. However, as already discussed, it is important for teachers to be aware of the differences, and for the differences to be explicitly discussed in teaching (cf., for example, Trigwell and Prosser 2014).

The teachers interviewed in this study expressed diverse and sometimes conflicting views. Nevertheless, we claim that our investigation and other published studies (e.g., Carstensen and Bernhard 2004, 2008, 2016; Carstensen 2013; Vince and Tiberghien 2002) show that highlighting the importance of applications of the Laplace transform when teaching it, and not explicitly linking the 'worlds' of 'objects' and 'events', seem to raise obstacles for learning. As mentioned in the introduction, a common research finding is that it is difficult for students to make these links (e.g. Roth and Bowen 2001; Kaput 1987; Carstensen and Bernhard 2012; Tiberghien 1999). Even in interdisciplinary courses, promoting the development of interdisciplinary thinking among students is not straightforward (e.g., Eisen et al. 2009; Spelt et al. 2015). A tentative implication of this study is that some of these difficulties can be attributed to many teachers failing to make these links explicit themselves, as seen in some of the 
diagrams of relations presented in $\S 5.1$, at least not as expressed in their views on the nature of the Laplace transform and its relations to physics and technology in engineering education.

We have investigated university teachers' views on the relationships between 'mathematics', 'physics' and 'technology' in the context of the Laplace transform in engineering education. Our results demonstrate that the interviewed teachers hold qualitatively different views, ranging from seeing these elements as very closely connected and inherently linked to seeing them as unconnected and irrelevant to each other. It seems reasonable to assume that there are similar qualitative differences in views held by university teachers teaching other subjects. To increase the 'consistency in [the educational] system' (Biggs 1999, 64) it is important to discuss and be aware of these differences in views. Therefore we perceive a need for engineering education researchers to investigate not only students' views and conceptions, but also those held by teachers to enable improvement in the quality of engineering education.

\section{Funding}

This research has in part been supported by grant VR 721-2011-5570 from the Swedish Research Council (Vetenskapsrådet). 


\section{References}

Baillie, C. 2006. "Threshold Concepts in Engineering Education: Exploring Potential Blocks in Student Understanding." International Journal of Engineering Education 22 (5):955-962.

Baillie, C., and J. Bernhard. 2009. "Educational Research Impacting Engineering Education." European Journal of Engineering Education 34 (4):291-294.

Berge, M., and A. Weilenmann. 2014. "Learning About Friction: Group Dynamics in Engineering Students’ Work with Free Body Diagrams." European Journal of Engineering Education 39 (6):601-616. doi: 10.1080/03043797.2014.895708.

Bernhard, J. 2010. "Insightful Learning in the Laboratory: Some Experiences from Ten Years of Designing and Using Conceptual Labs." European Journal of Engineering Education 35 (3):271-287. doi: 10.1080/03043791003739759.

Bernhard, J., A.-K. Carstensen, and M. Holmberg. 2010. Investigating Engineering Students' Learning - 'Learning as the Learning of a Complex Concept'. Paper presented at the IGIP-SEFI 2010, Trnava, 19-22 September.

Bernhard, J., A.-K. Carstensen, and M. Holmberg. 2013. Phase as a Key Concept in Physics and Electrical Engineering. Paper presented at the SEFI annual conference, Leuven, Sept 16-20.

Biggs, J. 1996. "Enhancing Teaching through Constructive Alignment." Higher Education 32 (3):347-364.

Biggs, J. 1999. "What the Student Does: Teaching for Enhanced Learning." Higher Education Research and Development 18 (1):57-75. doi: 10.1080/0729436990180105. 
Biggs, J. B., and C. S.-K. Tang. 2011. Teaching for Quality Learning at University: What the Student Does. 4:th ed. Maidenhead: Open University Press.

Booth, S. 2004. "Engineering Education and the Pedagogy of Awareness." In Effective Learning and Teaching in Engineering, edited by C. Baillie. New York: RouthledgeFalmer.

Booth, S. 2008. "Learning and Teaching Engineering Mathematics for the Knowledge Society." European Journal of Engineering Education 33 (3):381 - 389.

Booth, S., and Å. Ingerman. 2002. "Making Sense of Physics in the First Year of Study." Learning and Instruction 12 (5):493-507.

Borrego, M., and J. Bernhard. 2011. "The Emergence of Engineering Education Research as a Globally Connected Field of Inquiry." Journal of Engineering Education 100 (1):14-47.

Bowden, J. 2004. "Capabilities-Driven Curriculum Design." In Effective Learning and Teaching in Engineering, edited by C. Baillie. New York: RouthledgeFalmer. Carberry, A. R., and A. F. McKenna. 2014. "Exploring Student Conceptions of Modeling and Modeling Uses in Engineering Design." Journal of Engineering Education 103 (1):77-91. doi: 10.1002/jee.20033.

Carstensen, A.-K. 2013. Connect: Modelling Learning to Facilitate Linking Models and the Real World through Lab-Work in Electric Circuit Courses for Engineering Students, Doctoral Dissertation. Linköping: Linköping University: Linköping Studies in Science and Technology, Dissertation No. 1529.

Carstensen, A.-K., and J. Bernhard. 2004. Laplace Transforms - Too Difficult to Teach, Learn and Apply, or Just Matter of How to Do It. Paper presented at the EARLI sig\#9 Conference, Gothenburg, 18-21 August. 
Carstensen, A.-K., and J. Bernhard. 2008. "Threshold Concepts and Keys to the Portal of Understanding: Some Examples from Electrical Engineering." In Threshold Concepts within the Disciplines, edited by R. Land, E. Meyer and J. Smith, 143154. Rotterdam: Sense Publishers.

Carstensen, A.-K., and J. Bernhard. 2009. "Student Learning in an Electric Circuit Theory Course: Critical Aspects and Task Design." European Journal of Engineering Education 34 (4):389-404. doi: 10.1080/03043790902990315.

Carstensen, A.-K., and J. Bernhard. 2012. Make Links: Overcoming the Threshold and Entering the Portal of Understanding. Paper presented at the Threshold Concepts Conference, Dublin, 27-29 June.

Carstensen, A.-K., and J. Bernhard. 2016. "Make Links: Overcoming the Threshold and Entering the Portal of Understanding." In Threshold Concepts in Practice, edited by R. Land, E. T. Meyer and M. T. Flanagan, 209-220. Rotterdam: Sense Publishers.

Comenius, J. A. 1657. "Didactica Magna [in Latin]." In Opera Didactica Omnia, edited by J. A. Comenius, 5-190. Amsterdam.

Creswell, J. W. 2012. Educational Research: Planning, Conducting, and Evaluating Quantitative and Qualitative Research. 4th ed. Boston, MA: Pearson.

Dray, T., and C. A. Manogue. 2005. "Bridging the Gap between Mathematics and the Physical Sciences." In Preparing Future Science and Mathematics Teachers, edited by D. Smith and E. Swanson, 39-41. Bozeman: Montana State University. Edström, K., and A. Kolmos. 2014. "Pbl and Cdio: Complementary Models for Engineering Education Development." European Journal of Engineering Education 39 (5):539-555. doi: 10.1080/03043797.2014.895703. 
Eisen, A., A. Hall, T. S. Lee, and J. Zupko. 2009. "Teaching Water: Connecting across Disciplines and into Daily Life to Address Complex Societal Issues." College Teaching 57 (2):99-104. doi: 10.3200/CTCH.57.2.99-104.

Finelli, C. J., S. R. Daly, and K. M. Richardson. 2014. "Bridging the Research-toPractice Gap: Designing an Institutional Change Plan Using Local Evidence." Journal of Engineering Education 103 (2):331-361. doi: 10.1002/jee.20042.

González Sampayo, M. 2006. Engineering Problem Solving: The Case of the Laplace Transform as a Difficulty in Learning Electric Circuits and as a Tool to Solve Real World Problems. Linköping: Linköping Studies in Science and Technology Dissertation No. 1038.

Grubbström, R. 1967. "On the Application of the Laplace Transform to Certain Economic Problems." Management Science 13 (7):558-567.

Holmberg, M., and J. Bernhard. 2008. "University Teachers' Perspectives on the Role of the Laplace Transform in Engineering Education." In Mathematical Education of Engineers Conference - MEE2008. Loughborough.

Kaput, J. J. 1987. "Towards a Theory of Symbol Use in Mathematics." In Problems of Representation in the Teaching and Learning of Mathematics, edited by C. Janvier, 159-195. Hillsdale: Lawrence Erlbaum.

Kautz, C. 2011. Development of Instructional Materials to Address Student Difficulties in Introductory Electrical Engineering. Paper presented at the WEE2011, Lisbon, 27-30 September.

Kvale, S. 1996. Interviews: An Introduction to Qualitative Research Interviewing. Thousands Oaks, CA: SAGE Publications. 
Künzli, R. 2000. "German Didaktik: Models of Re-Presentation, of Intercourse, and of Experience." In Teaching as a Reflective Practice: The German Didaktik Tradition, edited by I. Westbury, S. Hopmann and K. Riquarts, 41-54. Mahwah, NJ: Lawrence Erlbaum.

Linder, C. J. 1992. "Is Teacher-Reflected Epistemology a Source of Conceptual Difficulty in Physics?" International Journal of Science Education 14 (1):111121. doi: 10.1080/0950069920140110.

Martin, E., M. Prosser, K. Trigwell, P. Ramsden, and J. Benjamin. 2000. "What University Teachers Teach and How They Teach It." Instructional Science 28 (5):387-412. doi: 10.1023/A:1026559912774.

Marton, F. 1975. "On Non-Verbatim Learning: 1. Level of Processing and Level of Outcome." Scandinavian Journal of Psychology 16 (1):273-279. doi: 10.1111/j.1467-9450.1975.tb00193.x.

Marton, F. 1981. "Phenomenography: Describing Conceptions of the World around Us." Instructional Science 10:177-200.

Marton, F. 1988. "Phenomenography: Exploring Different Conceptions of Reality." In Qualitative Approaches to Evaluation in Education: The Silent Scientific Revolution, edited by D. M. Fetterman, 176-205. New York: Praeger.

Marton, F. 2015. Necessary Conditions of Learning. New York: Routledge.

Marton, F., U. Runesson, and A. B. M. Tsui. 2004. "The Space of Learning." In Classroom Discourse and the Space of Learning, edited by F. Marton and A. B. M. Tsui, 3-40. Mahwah: Lawrence Erlbaum.

Marton, F., and R. Säljö. 1976. "On Qualitative Differences in Learning I - Outcome and Process." British Journal of Educational Psychology 46:115-127. 
Mulhall, P., and R. Gunstone. 2008. "Views About Physics Held by Physics Teachers with Differing Approaches to Teaching Physics." Research in Science Education 38 (4):435-462.

Niss, M. 1994. "Mathematics in Society." In Didactics of Mathematics as a Scientific Discipline, edited by R. Biehler, R. W. Scholz, R. Sträßer and B. Winkelmann, 367-378. Dordrecht: Kluwer.

Pajares, M. F. 1992. "Teachers' Beliefs and Educational Research: Cleaning up a Messy Construct." Review of Educational Research 62 (3):307-332.

Pollak, H. O. 1979. "The Interaction between Mathematics and Other School Subjects." In New Trends in Mathematics Teaching, edited by ICME, 232-248. Paris: UNESCO.

Prosser, M., E. Martin, K. Trigwell, P. Ramsden, and G. Lueckenhausen. 2005. "Academics' Experiences of Understanding of Their Subject Matter and the Relationship of This to Their Experiences of Teaching and Learning." Instructional Science 33 (2):137-157. doi: 10.1007/s11251-004-7687-x.

Roth, W.-M., and M. G. Bowen. 2001. "Professionals Read Graphs: A Semiotic Analysis." Journal for Research in Mathematics Education 32:159-194.

Spelt, E. J. H., P. A. Luning, M. A. J. S. van Boekel, and M. Mulder. 2015. "Constructively Aligned Teaching and Learning in Higher Education in Engineering: What Do Students Perceive as Contributing to the Learning of Interdisciplinary Thinking?" European Journal of Engineering Education 40 (5):459-475. doi: 10.1080/03043797.2014.987647.

Straesser, R. 2007. "Didactics of Mathematics: More Than Mathematics and School!" ZDM Mathematics Education 39 (1):165-171. 
Streveler, R. A., T. A. Litzinger, R. L. Miller, and P. S. Steif. 2008. "Learning Conceptual Knowledge in the Engineering Sciences: Overview and Future Research Directions." Journal of Engineering Education 97 (3):279-294. doi: 10.1002/j.2168-9830.2008.tb00979.x.

Sundlöf, A., A.-K. Carstensen, L. Tibell, and J. Bernhard. 2003. Real Models in Modelled Reality: Epistemic Confusion When Communicating Science? Paper presented at the European Science Education Research Association Conference, Noordwijkerhout, Netherlands, 19-23 September.

Tiberghien, A. 1999. "Labwork Activity and Learning Physics - an Approach Based on Modelling." In Practical Work in Science Education, edited by J. Leach, Paulsen, A. C., 176-194. Dordrecht, The Netherlands: Kluwer.

Trigwell, K., and M. Prosser. 2014. "Qualitative Variation in Constructive Alignment in Curriculum Design." Higher Education 67 (2):141-154. doi: 10.1007/s10734013-9701-1.

Trigwell, K., M. Prosser, and F. Waterhouse. 1999. "Relations between Teachers' Approaches to Teaching and Students' Approaches to Learning." Higher Education 37 (1):57-70. doi: 10.1023/A:1003548313194.

Vince, J., and A. Tiberghien. 2002. "Modelling in Teaching and Learning Elementary Physics." In The Role of Communication in Learning to Model, edited by P. Brna, 49-68. Mahwah, NJ: Lawrence Erlbaum.

Winkelman, P. 2009. "Perceptions of Mathematics in Engineering." European Journal of Engineering Education 34 (4):303-314. 